\title{
PROFISSIONAIS ADMINISTRATIVOS NA GESTÃO DO SISTEMA ÚNICO DE SAÚDE: A DIVISÃO SOCIAL DO TRABALHO
}

\author{
ADMINISTRATIVE PROFESSIONALS IN THE MANAGEMENT OF THE UNIFIED HEALTH SYSTEM: \\ THE SOCIAL DIVISION OF LABOR
}

\author{
Francini Lube Guizard ${ }^{1}$ \\ Maria Luiza Silva Cunha ${ }^{2}$
}

Resumo $\mathrm{O}$ artigo analisa a inserção dos profissionais administrativos de nível médio nos serviços de saúde, visando problematizar sua atuação nas estruturas e relações de poder que conformam tais instituições. São apresentados dados relativos à compreensão desses trabalhadores sobre o papel que desempenham e as relações que vislumbram entre seu processo de trabalho e a gestão do Sistema Único de Saúde. O estudo foi desenvolvido em uma região de saúde do município do Rio de Janeiro, por meio do mapeamento dos processos de trabalho administrativos de nível médio nas diferentes instituições públicas de saúde desse território. Foram realizadas 44 entrevistas semiestruturadas, abrangendo os diferentes processos identificados. Os resultados indicam que a hierarquização do processo decisório está associada à desvalorização desses profissionais, que se percebem como meros executores das definições traçadas pelos níveis hierárquicos superiores. Concluímos que a racionalidade administrativa instrumental permanece hegemônica no território. Esses aspectos levam à reflexão sobre as possibilidades de avançar a consolidação do SUS sem a adesão dos atores sociais implicados em sua construção cotidiana, dentre os quais destacamos os agentes administrativos em seu papel estratégico nos processos de gestão.

Palavras-chave trabalho em saúde; gestão em saúde; democracia institucional; autonomia.

\begin{abstract}
The article analyzes the insertion of mid-level administrative professionals in health services aiming at discussing the roles they play in the power structures and relations that make up such institutions. Data are presented concerning the workers' understanding of their roles and the relations they envision between their work processes and the management of the Unified Health System. The study was carried out in a health region of the city of Rio de Janeiro, and involved mapping the middle-level administrative work processes at the different public health institutions in this territory. In total, 44 semi-structured interviews were conducted, covering the different processes that were identified. The results show that decision-making prioritization is associated with the devaluation of these professionals, who see themselves as mere implementers of definitions set out by higher hierarchical levels. We conclude that instrumental administrative rationality remains hegemonic in the territory. These aspects lead to reflection on whether or not it is possible to further consolidate SUS without the active participation of the social actors involved in building it, among whom we highlight the administrative agents due to the strategic role they play in the management processes. Keywords health work; health management; institutional democracy; autonomy.
\end{abstract}




\section{Introdução}

A experiência de 23 anos com a reforma do sistema de saúde tem revelado a complexidade dos contextos sociopolíticos que conformam a realidade brasileira e que apresentam um amplo conjunto de desafios para a consolidação do Sistema Único de Saúde (SUS). As dificuldades enfrentadas, em parte atinentes à necessidade de reconfigurar a organização dos serviços e os modos de gestão do sistema de saúde, nos indicam também a importância em ampliar as estratégias de formação e qualificação profissional, uma vez que a consolidação do SUS requer trabalhadores capazes de fomentar e atuar na consecução das transformações almejadas (EPSJV, 2005).

No que tange à qualificação dos trabalhadores do campo da gestão em saúde, observa-se que historicamente tem sido dada prioridade à formação de segmentos que ocupam funções de direção, com investimentos em curso de especialização lato e stricto sensu (Abrahão, 2003). Esse direcionamento converge com a concepção de gestão que orienta o sistema desde a Norma Operacional Básica de 1996 (NOB 96), que define a gestão como “a atividade e a responsabilidade de dirigir um sistema de saúde (municipal, estadual ou nacional), mediante o exercício de funções de coordenação, articulação, negociação, planejamento, acompanhamento, controle, avaliação e auditoria" (Brasil, 2003, p. 52-53). A transformação dos modos de gestão em saúde, contudo, implica diretamente o cotidiano das instituições, o que nos remete à atuação dos profissionais administrativos de nível médio, que atuam diretamente na relação entre as decisões centrais da gestão e a área assistencial (ESPJV, 2005).

As questões acima colocadas explicitam a necessidade de analisar a inserção dos profissionais administrativos de nível médio nos serviços de saúde, a fim de problematizar sua atuação nas estruturas e relações de poder que conformam tais instituições, bem como para compreender as articulações dos processos de gestão em saúde com os contextos sociopolíticos em que se inserem.

Este artigo apresenta resultados parciais da pesquisa "Formação de trabalhadores e o Sistema Único de Saúde: analisando os desafios para a Gestão do Trabalho em Saúde", desenvolvida pelo Laboratório de Educação Profissional em Gestão em Saúde, da Escola Politécnica de Saúde Joaquim Venâncio, da Fundação Oswaldo Cruz (ESPJV/Fiocruz), ${ }^{3}$ no período compreendido entre novembro de 2007 e agosto de 2009. A pesquisa teve por objetivo mapear as necessidades que o SUS apresenta em relação à formação de trabalhadores orientada para a qualificação do processo de trabalho em gestão em saúde, investigando os processos de trabalho que operacionalizam as ações administrativas em nível intermediário. O presente artigo apresenta especificamente os resultados relativos à compreensão que os trabalhadores expres- 
saram sobre o papel que desempenham nas instituições de saúde e quais as relações que vislumbram entre seu processo de trabalho e a gestão do SUS.

\section{Metodologia da pesquisa}

A metodologia de pesquisa baseou-se em técnicas qualitativas de investigação, a fim de reconhecer a complexidade do objeto, seus parâmetros e suas especificidades, considerados como os critérios mais importantes de cientificidade (Minayo, 1992). Os objetivos delineados, associados à restrita disponibilidade de estudos e informações secundárias sobre o tema, conduziram à necessidade de se realizar primordialmente uma investigação exploratória, de caráter empírico-analítico. Dessa forma, as estratégias metodológicas foram traçadas com base na preocupação em mapear os processos de trabalho na área técnica da gestão, as trajetórias de formação que os subsidiam e as características da força de trabalho que os compõem, analisando qualitativamente essas variáveis e suas inter-relações, com o intuito de apreender a complexidade do cotidiano institucional. O projeto foi submetido aos comitês de ética da EPSJV e da Secretaria Municipal de Saúde do Rio de Janeiro, tendo sido aprovado em ambos.

\section{Campo empírico do estudo e estratégias de investigação}

O estudo foi realizado em uma região de saúde do município do Rio de Janeiro, escolhida em função da complexidade da rede de saúde desse território. A opção pelo recurso exclusivo a procedimentos qualitativos de pesquisa demandou um recorte no campo empírico, de modo a explorar tanto intensiva como extensivamente os processos de trabalho gerenciais nas instituições de saúde, as relações e os desafios colocados pelas necessidades da rede de serviços. Assim, optamos por analisar o subsistema Ilha do Governador, Área Programática 3.1 do município do Rio de Janeiro, pelas características de sua rede: trata-se de um território delimitado, com porte equivalente às cidades médias brasileiras e possui estabelecimentos de saúde nos três níveis de atenção.

Após a delimitação do campo empírico do estudo, o trabalho de campo teve início com o contato e a apresentação do projeto nas unidades de saúde do território. ${ }^{4}$ Em seguida, foi efetuado um levantamento junto a essas unidades, com a finalidade de identificar os setores em que havia trabalhadores com cargos de nível médio atuando em atividades administrativas. A preocupação central que norteou o procedimento não foi inventariar o quantitativo desses profissionais, mas sim identificar os diferentes processos de trabalho administrativos que cada instituição possui. 
Optamos, então, por realizar entrevistas semiestruturadas com um trabalhador de cada setor identificado, de modo a representar todos os processos de trabalho administrativos mapeados nos serviços de saúde, o que resultou em um total de 44 entrevistas. Essa etapa subsequente foi construída em função das informações reunidas pelo levantamento anterior, cujos resultados subsidiaram a seleção dos sujeitos da pesquisa.

Salientamos que a amostra dos sujeitos da pesquisa foi restrita a cargos de nível médio, o que não constitui a escolaridade como critério, já que $45 \%$ dos entrevistados possuem curso superior completo e $22,5 \%$, curso superior incompleto. Tampouco o vínculo empregatício e o tempo de função foram considerados para a amostragem, embora tenham sido incorporados como elementos importantes para a análise dos resultados. Dessa forma, $67 \%$ são servidores municipais; $22 \%$, servidores federais; $5 \%$, celetistas; $3 \%$, profissionais terceirizados; e 3\% não informaram o vínculo.

O roteiro de entrevista foi elaborado com base em revisão de literatura. Foram definidos dois eixos temáticos organizativos. O primeiro refere-se à experiência profissional prévia e atual no campo da gestão em saúde (posto de trabalho ocupado e principais aspectos do processo de trabalho); o segundo, à trajetória da formação profissional. O instrumento de pesquisa foi testado a partir de entrevistas-piloto, por meio das quais o questionário foi aperfeiçoado. ${ }^{5}$

O referencial metodológico utilizado para sistematização e interpretação do material empírico foi 'a análise de conteúdo', segundo as técnicas de análise temática e categorial (Bardin, 1997). Esse referencial foi escolhido por permitir obter, com o recurso a procedimentos sistemáticos e objetivos de descrição do conteúdo das mensagens, indicadores a partir dos quais foram construídas as inferências sobre o problema de pesquisa. Para fins de análise, destacamos especialmente os conteúdos manifestos que expressavam a experiência e a formação profissional, o contexto e inserção socioinstitucional dos sujeitos.

A partir de uma pré-análise dos temas emergentes nas entrevistas, definimos para o eixo experiência profissional prévia e atual no campo da gestão em saúde as seguintes categorias operatórias: trabalho em equipe; compreensão de gestão; processo de trabalho da gestão em saúde; percepção do SUS. Em relação ao eixo trajetória da formação profissional, as categorias operatórias foram: formação profissional realizada; motivos/interesse para busca de formação profissional; política institucional de formação dos trabalhadores; expectativa de formação profissional; concepções de formação profissional. Neste artigo, apresentamos os resultados relativos à categoria operatória 'compreensão de gestão', com foco na inserção dos trabalhadores administrativos no processo decisório da instituição. 


\section{Resultados de pesquisa: concepções de gestão em saúde dos trabalhadores administrativos de nível médio}

No presente artigo, dedicamo-nos a discutir a compreensão dos trabalhadores sobre o papel que desempenham nas instituições de saúde e quais as relações que vislumbram com os processos de gestão do SUS. Iniciaremos nossa reflexão sobre o tema, procurando compreender como o campo da gestão em saúde constituiu-se com base no processo de consolidação do SUS. Em breve retrospectiva, observamos um grande avanço em sua institucionalização, em especial no que diz respeito aos instrumentos normativos de organização da atenção e da gestão em saúde. Destacam-se, a esse respeito, o impacto das normas operacionais na década de 1990, a reorganização da Atenção Primária com a Estratégia de Saúde da Família e a perspectiva de ampliação da pactuação federativa das políticas, com o Pacto pela Saúde e os instrumentos implementados pelo decreto n. 7.508, de 2011, como o Contrato Organizativo de Ação Pública e o mapa da saúde. Esses são importantes exemplos de artifícios institucionais produzidos no campo da gestão em saúde e que responderam pela estruturação do SUS em âmbito nacional, por sua significativa capilaridade em tão abrangente contexto e em um período histórico relativamente curto.

As práticas da gestão no SUS foram sendo construídas e consolidadas nessa trajetória normativa que descentralizou e organizou, sob fortes mecanismos de indução financeira, o sistema de saúde em âmbito nacional. Como explicitado na norma operacional de 1996, a concepção de gestão que norteou esse processo de organização restringe-se aos atores que ocupam cargos de direção nas unidades e no sistema de saúde. Tal concepção, ao focar-se em cargos e atribuições de direção, revela o não reconhecimento e a não valorização dos processos de trabalho de diferentes profissionais administrativos, que desempenham um amplo conjunto de atividades essenciais à organização do SUS. Esse aspecto justifica a relevância de nosso problema de pesquisa, qual seja, compreender os processos de trabalho dos profissionais de nível médio que atuam na gestão. Isso porque, como é possível constatar nas definições apresentadas na NOB 96, há uma grande lacuna sobre essa questão, o que indica a necessidade de pensarmos a gestão e a atuação desses trabalhadores desde o contexto das relações institucionais que configuram os serviços de saúde, pois é nesse plano que o sistema se materializa socialmente.

As entrevistas realizadas demonstram que os trabalhadores compartilham a compreensão de gestão apresentada na NOB 96. Em resposta à pergunta sobre quem são os responsáveis pela gestão da unidade em que trabalham, 92,5\% identificaram os cargos de direção da unidade. Uma parcela dos entrevistados $(22,5 \%)$ referiu também as chefias imediatas, 
sendo que, destes, apenas 7,5\% mencionaram-nas exclusivamente. O que esses resultados indicam é a percepção de que a responsabilidade pela gestão é prerrogativa das posições de chefia na hierarquia institucional (setores, departamentos e da própria unidade). Interessante observar que apenas 7,5\% dos entrevistados reportaram os profissionais como sendo também responsáveis. As poucas falas nessa direção apresentam a noção de que o trabalho representa um compromisso, pelo qual os sujeitos devem responder: "A gestão tem a ver com tudo isso, você fazer direito o teu [sic] trabalho, da forma certa, organizada, dentro do que se propõe o trabalho do setor" (Entrevistado G3E6).

O fato de a grande maioria $(62,5 \%)$ identificar exclusivamente a direção (diretor, vice-diretor, diretor administrativo) como responsável pela gestão da unidade pode ser um importante sinalizador da centralização dos processos decisórios na instituição. A posição hierárquica surge, então, como um dos principais sentidos do termo gestão para os trabalhadores entrevistados, indicando, principalmente, acúmulo de poder decisório na organização do trabalho. Quando perguntados sobre o que é gestão, 30\% relataram diretamente essa compreensão, aludindo a termos como: supervisionar, comandar, tomar decisões, mandar, dirigir, chefiar, delegar, distribuir funções. “Gestão é gerir alguma coisa, é mandar" (E-GlE6); “a gestão, para mim, seria dirigir algo no trabalho, organizar, chefiar" (E-G1E10).

Tomamos como analisador do processo de construção do SUS a forma como a hierarquia institucional e a ocupação de cargos de chefia (que são também cargos políticos de confiança) são mencionadas como questões centrais na forte tendência à concentração de poder institucional, o que se choca com o compromisso democrático que fundamenta a luta pelo direito à saúde no Brasil. Para entender esse aspecto, é importante situar a história e a cultura política da sociedade brasileira, acentuadamente autoritária e excludente, de caráter patrimonialista, clientelista e personalista (Tavares, 1999; Sales, 1994). O campo da gestão em saúde não pode supor-se protegido dessa herança, mesmo quando advoga a democratização do Estado e da sociedade brasileira.

Quanto a isso, entendemos que o cotidiano da gestão nas instituições de saúde é contexto estratégico para a análise dos avanços e obstáculos enfrentados no SUS, pois nos permite observar uma série de contradições, vivenciadas, muitas vezes, em práticas de gestão propostas e defendidas por grupos identificados com o ideário do movimento sanitário. Práticas estas justificadas como forma de garantir a efetivação do SUS em um período histórico caracterizado por uma assistência pública à saúde fortemente mercantilizada. Um cenário adverso marcou toda a década de 1990, com a hegemonia das políticas públicas de cunho neoliberal, somadas à histórica fragmentação institucional do setor saúde, aos grupos de interesse vinculados 
ao complexo médico-industrial que acumularam grande poder de intervenção, bem como aos traços preponderantes de nossa cultura política. Todos esses aspectos podem ser evocados como justificativas para a aposta realizada na indução da institucionalização do SUS via práticas de gestão que centralizaram o poder decisório sobre a formulação e condução das políticas de saúde. Centralização que se expressa concretamente no modo como operam as instituições.

Um exemplo é a compreensão explicitada por alguns entrevistados sobre o gerenciamento do trabalho e do financiamento. Aqueles cujas atribuições são diretamente relacionadas aos processos de compra, faturamento e destinação dos recursos identificam por esse motivo a vinculação de seu trabalho à gestão: "Eu acho que gestão é gerir os recursos da unidade" (E-G3E5). Ao associarem diretamente gestão e financiamento, essas falas não podem ser entendidas sem que façamos o movimento de extrapolar o âmbito local dos serviços e reportar às características históricas do processo de organização do SUS, fortemente induzido pelo financiamento, fator utilizado como principal estratégia de articulação da descentralização do sistema, e que respondeu diretamente pela ampliação da capacidade gestora nos municípios. Esse entendimento pode ser observado na fala a seguir, que partiu da pergunta se a função exercida se relacionava com a gestão.

Está porque a gente levanta esses dados estatísticos que servem para o faturamento, que são repasses feitos do Ministério da Saúde para a prefeitura. Então esses dados que eu envio ajudam na gestão desse faturamento, desse retorno que vem para a prefeitura. Ou seja, a quantidade de atendimentos, a capacidade que a instituição tem de atendimento. Tudo isso vai ser enviado e depois é repassado de alguma forma para a prefeitura (E-G1E7).

Para $40 \%$ dos trabalhadores entrevistados, gestão e administração se identificam e dizem respeito à organização do serviço, das tarefas realizadas, dos meios e recursos empregados. Uma acepção bastante próxima do campo disciplinar da administração, principalmente quando observamos que esses sentidos são, com frequência, associados à necessidade de cumprimento dos objetivos traçados e do propósito de garantir eficácia e eficiência, otimizando recursos. Quanto a isso, parece-nos relevante que os objetivos da gestão sejam definidos em termos funcionalistas, em expressões como "trazer o melhor funcionamento"(E-G1E12); “o melhor desenvolvimento das tarefas" (E-G2E7); “organizar e otimizar o seu setor ou órgão" (E-GlEl1). Nessa direção, o melhor funcionamento é, habitualmente, entendido como aquele capaz de manter certa ordem, 'cumprir o trabalho' e atingir os objetivos definidos: “Gestão é poder fazer seu trabalho, fazer funcionar a máquina ali, da melhor forma possível, digerir aquilo ali, da melhor forma possível" (E-G2E4). 
O que consideramos importante debater é a utilidade de concepções e experiências de gestão pautadas pela permanência de formas de organização institucional tradicionais, quando o SUS depende, ao contrário, da possibilidade de ruptura com traços marcantes de nossa cultura política e da invenção de novas formas de sociabilidade. Desafios aos quais ainda faltam respostas adequadas no campo da gestão. A centralidade das práticas tradicionais da administração representa limite importante nessa direção, posto que fundamentadas em pressupostos contraditórios com o horizonte de democratização das relações sociais.

A principal evidência disso é a divisão que tais práticas procedem entre concepção e execução do trabalho, demarcando uma separação baseada em relações de poder que têm como efeito a objetivação da imensa maioria dos trabalhadores, vistos como recursos adicionais de produção, os ditos recursos humanos. Os trabalhadores de nível médio, grupo fortemente atrelado a esse lugar nos processos produtivos, relatam com clareza a percepção de que a gestão está relacionada à possibilidade de mudança, de formulação do trabalho, de proposição de novas ideias, ao desenvolvimento de técnicas, novas normas e projetos. Possibilidades nas quais não se reconhecem. Em uma das entrevistas, a justificativa dada para a compreensão de a função não estar relacionada à gestão foi a seguinte:

Não, eu... Assim, posso atuar com os objetivos traçados pela gestora que... Mas é só assim, eu sou um executor das diretrizes traçadas pela gestora, mas não, assim, estou envolvido diretamente com a gestão. Até porque não tem um... um setor, assim... com todos... muitos dos setores públicos não têm um feedback... (...) Uma reunião pelo menos com certa frequência para ver como nós vamos organizar um trabalho (E-G1E5).

Para esse entrevistado, o fato de não haver espaços coletivos de decisão interfere em sua participação na gestão. Ao ser perguntado se a existência de tais espaços representaria a possibilidade de atuação na gestão, ele respondeu afirmativamente, explicitando a sua percepção da importância dessa instância.

Porque eu poderia propor alguma ideia que alteraria o modo de trabalho e às vezes seria um ponto, uma participação minha na gestão: ‘Ele deu uma ideia, a gente vai seguir esse tipo de ideia que ele deu, então o trabalho vai ser feito agora desse jeito'. Então seria uma participação na gestão através de uma ideia (E-G1E5).

A ênfase nos processos decisórios e na concepção do trabalho está presente de modo difuso nas entrevistas, o que nos indica que a dimensão normativa é reconhecida como fundamental à gestão e refere-se à possibili- 
dade de definir a organização e o sentido do trabalho (Guizardi, 2008; Guizardi e Cavalcanti, 2010). Esclarecemos que, quando tomamos essa dimensão para análise, não estamos nos referindo somente às regras vigentes (formalizadas ou não), mas principalmente à requisição colocada pela atividade administrativa - bem como toda atividade de trabalho - de produção e atualização normativa (Schwartz, 2007). Quanto a isso, embora os resultados apresentem essa referência, fazem-no de modo ambíguo, particularmente nos sentidos associados ao termo 'coordenação'. Termo que, por um lado, é entendido como papel de facilitar os processos de trabalho, constituindo uma liderança que difere da função de comando e, por outro, é também referido à atribuição de delegar tarefas, estruturar o setor ou mesmo manter a ordem organizacional que marca as práticas administrativas tradicionais. Nesse caso, a gestão é associada à padronização do trabalho, à produção heterodeterminada das normas que o regulam: "De um modo geral, gestão é quem coordena um trabalho, é um facilitador, é um otimizador" (E-G1E19); “É liderança e coordenação. E é manter no artigo geral, os serviços de acordo com todas as normas vigentes" (E-GlEl4).

Quando questionados se a função que desempenham está relacionada à gestão, $80 \%$ responderam que sim. É necessário, contudo, analisar como percebem essa aproximação, a fim de compreender os desenhos que adquirem as relações institucionais, em particular no que tange à inserção dos profissionais de nível médio. Apesar da aparente homogeneidade desse resultado, é interessante constatar que vários entrevistados indicam a relação de sua função com a gestão sem considerar que atuam diretamente na gestão: “Não sou uma gestão, eu sou uma administração" (E-G1E2); “Eu, eu não sou gestor, é claro, mas eu estou colaborando com a gestão do administrador gestor da unidade" (E-G3E5). Outros, como apontado anteriormente, justificam-na em razão da vinculação de seu trabalho aos processos de compra e financiamento da unidade: "Eu ali seria, deixa eu ver, seria controlar os materiais, as entradas, as saídas, pra que não se desperdice, a quantidade certa, enviar as notas pra prefeitura, eles querem saber como é gasto o dinheiro, o que é gasto, qual o setor que gasta mais, sabe? Seria isso" (E-G3E2).

Uma entrevistada sinalizou que essa relação é devida à necessidade de saber organizar o próprio trabalho, para assegurar uma atuação adequada, garantindo a organização do serviço. Tal perspectiva situa o trabalho realizado no cumprimento do que está estabelecido como correto: “Tem relação com a gestão porque, se a gente não souber organizar o nosso trabalho, não vai conseguir fazer a função correta. Então a gente tem que saber se organizar também para poder organizar o serviço" (E-G1E20).

Há também, em contrapartida, aqueles que explicam essa relação sinalizando a interligação como aspecto determinante da gestão. Ou seja, não é 
possível fazer gestão sem recorrer ao conjunto dos processos de trabalho que conformam o serviço de saúde, de modo que todos os trabalhadores estão nela implicados. Essa acepção ampla das relações que determinam a gestão destoa do conjunto das narrativas encontradas e representa uma perspectiva interessante para problematizar as práticas administrativas tradicionais. Necessário salientar que, dentre todos que a referiram, apenas uma pessoa não possui curso superior (completo ou não), o que pode ser utilizado como indicador do impacto da escolaridade nas possibilidades de análise e contextualização do trabalho em suas inter-relações com os demais processos da instituição. Como exemplo desta compreensão, um dos trabalhadores afirmou que "dentro de suas limitações cada um tem responsabilidade sobre essa gestão. Todo mundo trabalha para essa gestão" (E-G1E4). Já outro mencionou que "Todos nós de alguma forma, em algum momento, somos elementos, somos, é..., elementos. sim, né? Para poder montar esse quebra-cabeça que é a gestão em si. Nós não podemos, não somos à parte, nós estamos inseridos, né?" (E-G3E4)

A capacidade de analisar o conjunto das relações institucionais e o trabalho surge para 17,5\% dos entrevistados como fator definidor da gestão. Nesses termos, gestão refere-se à qualificação da atuação profissional, aos conhecimentos teóricos nela mobilizados, à contextualização das questões institucionais, ao modo como é conduzida e articulada a interação entre os diferentes setores e ao acesso e uso de informações estratégicas para avaliação e organização do trabalho. Em todos esses sentidos atribuídos à gestão sobressai um aspecto comum, que diz respeito à superação da compartimentalização dos processos de trabalho, resultante da racionalidade administrativa característica da modernidade.

Gestão... Nossa! Eu estou fazendo um curso de gestão (risos). Gestão, o que eu tenho entendido, vai além do que eu estou fazendo no momento (...) mas você pensar em vários setores, em vários fluxos, vários... de uma forma geral, e não exatamente específico num trabalho só, mas você englobar vários serviços, você interagir em vários serviços. Isso eu acho que é gestão (E-G2E9).

Assim, a associação realizada entre gestão e os conhecimentos teóricos implicados na organização do trabalho pode ser reportada à separação já evocada entre sua concepção e execução. Em tal polarização, podemos sugerir que, para os entrevistados, a gestão situa-se como o polo que responde pela elaboração normativa e articulação institucional de processos de trabalho marcadamente fragmentados; ou, mesmo, pela administração dessa fragmentação. Quando não se reconhecem como gestores, os trabalhadores apontam justamente para essa relação de poder. Se analisarmos as oito entrevistas nas quais não foi identificada uma relação entre a função desem- 
penhada e a gestão da unidade, podemos constatar que em sete delas essa tensão é enunciada, ainda que não diretamente como justificativa da resposta dada. Aspecto que nos chamou a atenção em frases como:

Normalmente chega a determinação para eu cumprir a ordem, mais nada além disso (E-G2E1).

Eu acho que eu não opino muito, porque como tem uma diretora no meu setor, então, assim, ela é que está mais... mais envolvida (E-G2E5).

Não, eu acho que não. Diretamente, não. Assim, é... eu acho que a gente faz parte da engrenagem, né? Da unidade. Mas não sei se seria diretamente ligado. Acho que não, a direção é totalmente diferente do nosso trabalho. Agora, como [um] todo, toda máquina, né? As peças são interligadas, né? Mas diretamente ligadas não (E-G3E3).

Não. A minha função, eu me considero auxiliar da gestão (E-G1E16).

Em duas entrevistas, surgiu explicitamente uma diferenciação entre gestão e administração, que nos parece expressar questões mais amplas quanto à inserção dos profissionais de nível médio nos processos de gestão das unidades. Isso porque a compreensão que expõem sobre esses termos também pode ser percebida de modo difuso em várias entrevistas, que constroem narrativas próximas na abordagem de outros temas. Trata-se de uma distinção que não remete à natureza da atividade desenvolvida, mas propriamente à valorização e legitimação que possuem os diferentes atores. A gestão é vista como socialmente valorizada e reconhecida, enquanto o trabalho administrativo padeceria de certa invisibilidade, assentada no não reconhecimento de sua importância para a viabilização dos objetivos da unidade de saúde.

E eu estava conversando isso essa semana nessa reunião que eu convoquei com os profissionais da farmácia e da enfermagem, e discutir o fluxo dessa necessidade de alguém levar uma medicação, é que pra chefe da farmácia tudo é pra ontem. E isso gera tipo uma angina, sabe? (risos) Você fica... Acaba com você. Já acaba com o seu dia. Aquele mau humor de dizer que você tem que fazer na hora. É como se você não tivesse fazendo nada, é como se você não fosse presente na unidade, se as pessoas não te vissem aqui todo dia, não olhassem para a tua cara. Sabe? Eu chego cedo, saio tarde. (...) Não sai nada daqui sem a minha responsabilidade... (E-G2E9)

Aí saiu daqui olhando... Você viu o gesto que ela fez? Tipo assim, 'não serve para nada' . (...) Até porque a muitas pessoas incomoda eu ser nível médio e estar com 
cargo de administração. (...) Aliás, em todos os setores que eu fui sempre incomodou (E-G2E9).

A referência à falta de valorização presente na fala anterior é ainda mais emblemática por ter sido enunciada por alguém que responde há 15 anos pela direção administrativa da unidade, sendo reconhecido por todos os demais trabalhadores entrevistados na instituição como uma das pessoas responsáveis por sua gestão, em conjunto com a direção geral. Procurando justificar essa diferença de valorização, a entrevistada argumenta que os gestores possuem responsabilidades maiores do que aquelas presentes em seu próprio trabalho. No entanto, em muitos trechos da conversa, foram relatadas experiências contraditórias a essa justificativa.

Um exemplo é que, mesmo quando precisou afastar-se do trabalho por sérios problemas de saúde, ainda assim continuou respondendo na prática pelas questões relativas à diretoria administrativa, o que fazia por telefone, em período de repouso. Ela também mencionou que poderia ter se aposentado, mas que não consegue fazê-lo em razão dos pedidos de permanência da direção, que não teria como substituí-la em suas atribuições. Ou, ainda, exemplifica algumas questões de sua relação com os trabalhadores terceirizados contando episódios acontecidos no período noturno do fim de semana, quando contatada por outros profissionais da saúde da unidade, ou mesmo quando ligava para acompanhar a rotina do serviço. Estes não nos parecem ser exemplos de atribuições que envolvem pouca responsabilidade quanto à gestão. Um dos elementos explicativos mobilizados em sua fala é a diferença de prestígio social entre unidades básicas de saúde e os hospitais. Para ela, a gestão seria mais reconhecida nestes últimos equipamentos de saúde, sendo minimizada no caso das unidades de menor complexidade do sistema: “Eu acho que nós já fazemos um trabalho de gestão que não é assim, como que fala... Tipo assim, não é visto. Só é visto no caso dos hospitais" (E-G1E2).

Em nossa análise, a pouca visibilidade que possui o trabalho administrativo realizado por profissionais de nível médio resulta de certo modelo de gestão, ainda hegemônico no campo da saúde, apesar da sua incoerência com o significado sócio-histórico do SUS na construção e efetivação do direito à saúde. Nesse sentido, podemos afirmar que a trajetória da saúde pública brasileira tem revelado poucas modificações nos padrões de administração dos serviços de saúde, de modo que o cotidiano das relações institucionais tem sido determinado por grande centralização do poder, pouca flexibilidade nas respostas dadas às novas situações e forte viés normativo, hierárquico e burocratizado (Merhy, 2005). Estas três últimas características podem ser entendidas como nucleares de um paradigma centralizador e autoritário de gestão pouco problematizado no contexto dos serviços de saúde, nos quais prevalece como objetivo central da gestão o controle, a 
otimização e a racionalização das práticas administrativas. Características que convergem com a tradição que tem orientado as estratégias de administração modernas, cuja emergência histórica é marcada por necessidades específicas do modo de produção que se configura a partir do final do século XIX, com o desenvolvimento do capital monopolista.

Nesse contexto, o surgimento da gerência sinaliza, principalmente, a redução da autonomia dos trabalhadores sobre a tarefa, condição legitimada pela separação nas organizações sociais entre o momento da concepção e o da execução. Concordamos com a análise feita por Campos (2000), segundo a qual, não obstante seus compromissos democráticos, a efetivação do SUS seguiu os cânones dessa racionalidade gerencial hegemônica, marcada pelo exercício da disciplina, por todo o conjunto de recursos e métodos de direção que tornam a gestão uma ciência do comando e do controle (Lourau apud Campos, 2000), que procura substituir os desejos e interesses dos sujeitos trabalhadores por objetivos, normas e regras impostos.

A gestão clássica sempre trabalhou a dimensão do gerir. O gerir como ação sobre a ação dos outros. Assim sendo, fortemente amarrada ao exercício de poder. Seria ingênuo afirmar que essa abordagem da gestão não pressupõe produção. Pois ela produz o tempo todo. A gestão tem sido a disciplina do controle por excelência. Preocupada sempre com o aumento da produção de mais-valia, de produtividade, e de reprodução do status quo (Campos, 2000, p. 124).

Mesmo com o exercício discursivo da reengenharia organizacional, que advoga a recondução dos processos de trabalho em direção a uma maior flexibilidade, interdisciplinaridade e criatividade, defendendo a composição de parcerias e a gestão do conhecimento na solução de problemas, com aparente ampliação da autonomia no trabalho, ainda assim podemos constatar que o eixo primordial da tradição taylorista permanece atual. Para Campos (1994, 2000), não é excessivo manter a designação de racionalidade gerencial hegemônica, dada a manutenção da disciplina e do controle dos trabalhadores como aspecto fundamental dos modelos de administração contemporâneos, finalidade a partir da qual “(...) se faz política, inventam-se normas e se promovem alguns valores em detrimento de outros" (Campos, 2000, p. 34).

$\mathrm{O}$ mecanismo fulcral de efetivação dessa racionalidade administrativa gira em torno do princípio de autoridade. A associação entre as diferentes posições na hierarquia e relações de obediência e comando explicam em grande parte o modo de organização do trabalho, produzindo um leque delimitado de efeitos pedagógicos, assentados, sobretudo, na objetivação do trabalhador. A concentração de poder, a autoridade e a obediência são efeitos produtivos - já que produzidos e produtores - das estruturas hierárquicas das instituições, fenômeno cuja transversalidade é por si só enunciativa. 
Há classes que têm o poder de demitir, que tomam decisões, planejam, elaboram projetos e que, portanto, cultivam o hábito de pensar, de conceber ideias e planos e de fazer política. Concentração máxima de poder. E há aquelas sobre as quais recaem as decisões. Estas, a maioria, são educadas para o medo, para o culto do bom comportamento, da adulação e do servilismo; para a valorização do silêncio; enfim, para a suposição de que não saberiam nem poderiam vir a saber (Campos, 2000, p. 31).

A aguda crítica feita pelo autor nos convida a refletir que a tentativa de exercer um controle eficaz sobre o trabalho apenas é viável se acompanhada de formas de contenção, ou mesmo de eliminação, das subjetividades e suas singularidades. Em certa medida, podemos imaginá-las como instrumentos de garantia do sistema apesar dos sujeitos que o compõem. Não seria, afinal, coincidência que grande parte dos problemas identificados no cotidiano do sistema diga respeito às normas que organizam a produção dos serviços no SUS (Castanheiras, 1990).

Campos (2006) observa, inclusive, que a predominância das regras de mercado na produção de serviços obstaculiza o desenvolvimento de técnicas gerenciais voltadas à particularidade do campo da saúde, gerando o que designa como um "primitivismo da gestão", sua condução sem planejamento e sem estratégias de avaliação de sua qualidade. Esse primitivismo seria, paradoxalmente, a outra face da incorporação dos modelos tradicionais da administração, cujas características têm como principal efeito a produção de sujeitos seriais (Campos, 2006).

Nessa mesma direção, Abrahão, Martins e Geisler (2008, p. 248) sinalizam que a organização contemporânea do mundo do trabalho incorporou expressões como 'flexibilidade', 'criatividade', 'terceirização', 'parceria' e 'gestão do conhecimento', entre outras, como 'as diretrizes da moda'. Contudo, na avaliação das autoras, essas tendências não resultaram em maior autonomia, mas no aprofundamento da heteronomia do trabalho.

Azevedo, Braga Neto e Sá (2002, p. 238) salientam que o "paradigma clássico e ainda dominante de gestão" não consegue transpor uma compreensão simplista e instrumental da relação entre indivíduo e organização. Mesmo quando reconhecem a importância dos fatores subjetivos, abordagens como Qualidade Total pressupõem um sujeito passivo, que deve introjetar e incorporar a cultura e as metas da organização. Para os autores, mesmo o planejamento estratégico situacional de Carlos Matus, corrente com significativa expressão na área da saúde, desconsidera questões centrais dessa relação ao responder ao problema da governabilidade com duas alternativas polares: a anulação do opositor ou a articulação de acordos normativos com base em procedimentos racionais de decisão.

Divergindo da aposta na racionalização ou no controle, Azevedo, Braga Neto e Sá (2002) enfatizam, com base na psicossociologia francesa, as dinâ- 
micas grupais presentes na vida organizacional. Dessa forma, destacam que fatores imaginários e inconscientes nela intervêm por meio de processos de identificação e idealização, que tornam os laços e investimentos afetivos determinantes na relação entre sujeito e organização. Como resultado, avaliam que "para a construção de um projeto comum, é necessário que as representações sobre a organização sejam não apenas intelectualmente pensadas, mas afetivamente sentidas" (Azevedo, Braga Neto e Sá, 2002, p. 241).

Contudo, observamos nas entrevistas realizadas que, na inserção dos trabalhadores administrativos de nível médio, prevalecem a obediência e a compressão de interesses e desejos. Esses aspectos denotam mecanismos de objetivação e de adaptação semipassiva ao contexto, que, segundo Campos (2000), seriam dimensões produtivas essenciais da forma como hegemonicamente é organizado o trabalho. Em resumo, as instituições de saúde pesquisadas mantêm um sistema de governo do trabalho que não apenas pressupõe e recoloca insistentemente a ruptura 'intransponível' entre dirigentes e executores, como também diferencia suas alternativas de desenvolvimento e qualificação profissional, suas expectativas quanto à realização pessoal e ao acesso ao poder (Campos, 2000).

\section{Considerações finais}

Os resultados obtidos indicam a permanência da racionalidade administrativa instrumental no território pesquisado. Esses achados corroboram a literatura sobre o trabalho em saúde, que sinaliza que as transformações contemporâneas do mundo do trabalho não transpõem as características centrais dos modelos de gestão hegemônicos no século XX, calcados na objetivação e no controle dos trabalhadores. Quando contrapomos essa evidência às estratégias de gestão que caracterizaram a implementação do SUS nos últimos 22 anos, alguns questionamentos tornam-se relevantes. Dentre eles, cabe interrogar por que a construção local dos desenhos e práticas institucionais não tem se constituído como base de um processo de formulação ascendente da política de saúde. Ao contrário, o que se observa no cotidiano das instituições pesquisadas é a manutenção da lógica de centralização normativa que marcou a implementação do SUS na década de 1990 (Guizardi e Cavalcanti, 2010), para a qual os serviços de saúde são, sobretudo, o último ponto de uma cadeia decisória.

A inserção dos trabalhadores administrativos de nível médio nos diferentes processos de trabalho das organizações estudadas demonstra ser marcada por pouco reconhecimento social e autonomia. Os relatos colhidos apontam que esses profissionais são comumente percebidos como executores de definições e estratégias formuladas em núcleos restritos de poder 
institucional. Um dos aspectos mais significativos dos resultados encontrados consiste no fato de que, como adverte Campos (2000), tal modo de gestão produz não apenas práticas e serviços de saúde, mas também os sujeitos de suas relações. Nesse sentido, destaca-se a forma como os trabalhadores entrevistados enunciam de modo naturalizado a pouca valorização e autonomia no trabalho.

Quando contrapomos esse fato à inserção estratégica que possuem na operacionalização de todos os processos gerenciais das unidades, cabe indagar como se tem conformado o cotidiano das práticas institucionais no SUS, tendo em vista as rupturas necessárias com a cultura político-institucional prévia à garantia da saúde como direito. Como garantir direitos de cidadania aos usuários dos serviços, se parte significativa de seus trabalhadores não a exercem nas relações de trabalho?

Assim, ao indicar os limites da racionalidade instrumental que marca o campo da administração na saúde, não deixamos de reconhecer a centralidade que a gestão possui na concretização dos princípios e objetivos de justiça social que fundamentam o SUS. Nesse sentido, a natureza política de seu sucesso depende da possibilidade de publicizar e problematizar o espaço de ação da gestão como sendo justamente aquele em que se evidenciam as contradições do sistema e no qual são engendradas tanto a sua transformação como a reprodução e a atualização de relações historicamente hegemônicas.

As limitações dos modos de gestão vigentes colocam em primeiro plano o fato de que o SUS não avançará sem contar com a adesão dos atores sociais que o constroem no cotidiano, dentre os quais os agentes administrativos do sistema de saúde desempenham papel estratégico. Essa questão denota a importância da inclusão ativa e autônoma desses atores nos processos de organização do trabalho e de produção concreta de ações assistenciais. Em outras palavras, em nossa avaliação permanece atual a necessidade de democratização da gestão, como meio de restringir e superar o poder e a preeminência que os interesses privados repetidamente têm adquirido sobre os coletivos, subordinando-os justamente ao controlar os processos e pontos estratégicos da organização do trabalho.

\section{Notas}

1 Professora-pesquisadora da Escola Politécnica de Saúde Joaquim Venâncio, da Fundação Oswaldo Cruz (EPSJV/Fiocruz), Rio de Janeiro, Brasil. Doutora em Saúde Coletiva pelo Instituto de Medicina Social da Universidade do Estado do Rio de Janeiro (IMS/Uerj).<flguizardi@gmail.com> 
Correspondência: Fundação Oswaldo Cruz, Escola Politécnica de Saúde Joaquim Venâncio, sala 311, Av. Brasil, 4.365, CEP 21040-900, Manguinhos, Rio de Janeiro, RJ, Brasil.

2 Professora-pesquisadora da Escola Politécnica de Saúde Joaquim Venâncio, da Fundação Oswaldo Cruz (EPSJV/Fiocruz), Rio de Janeiro, Brasil. Mestre em Saúde Pública pela Escola Nacional de Saúde Pública Sergio Arouca, da Fundação Oswaldo Cruz (Ensp/Fiocruz). $<$ luizacunha@fiocruz.br>

$3 \mathrm{O}$ projeto foi realizado com o apoio financeiro da Fundação Carlos Chagas Filho de Amparo à Pesquisa do Estado do Rio de Janeiro (Faperj).

4 O Hospital Universitário Clementino Fraga Filho e o Instituto de Puericultura e Pediatria Martagão Gesteira não foram incluídos na amostra, pois estão localizados fora do território da Ilha do Governador e, apesar de estarem formalmente situados na rede desse subsistema, são hospitais de referência regional e nacional, com porta de entrada fechada, apresentando em razão disso especificidades que extrapolam o escopo de nossa investigação. O PSF Parque Royal também não foi incorporado, pois não possui trabalhadores administrativos de nível médio. A amostra incluiu as demais unidades de saúde e a Coordenação de Área Programática, por causa de seu papel estratégico na gestão e organização deste subsistema.

5 Foram feitos testes com dois profissionais administrativos de nível médio da Fundação Oswaldo Cruz e dois estudantes da habilitação técnica em gerência em saúde da ESPJV, que cursavam o estágio curricular. Houve a necessidade de modificações no linguajar e na ordem das questões como resultado da discussão das entrevistas com os colaboradores que participaram do teste-piloto.

\section{Referências}

ABRAHÃO, Ana Lúcia. Novas práticas na gestão em saúde e reforma da educação profissional: uma proposta curricular em eixos transversais para técnicos de gestão em serviços de saúde, 2003. Mimeografado.

ABRAHÃO, Ana Lúcia; MARTINS, Carla Macedo; GEISLER, Adriana. O sujeito na literatura acadêmica sobre gestão em saúde: notas para a questão da autonomia. Ciência \& Saúde Coletiva, Rio de Janeiro, v. 13, n. 1, p. 247-257, 2008.

AZEVEDO, Creuza da Silva; BRAGA NETO, Francisco Campos; SÁ, Marilene de Castilho. Indivíduo e a mudança nas organizações de saúde: contribuições da psicossociologia.
Cadernos de Saúde Pública, Rio de Janeiro, v. 1, n. 18, p. 235-247, 2002.

BARDIN, Laurence. Análise de conteúdo. Lisboa: Edições 70, 1997.

BRASIL. Conselho Nacional de Secretários de Saúde. Legislação do SUS. Conselho Nacional de Secretários de Saúde. Brasília, DF: CONASS, 2003.

CAMPOS, Gastão Wagner. Considerações sobre a arte e a ciência da mudança: revolução das coisas e reforma das pessoas. In: CECILIO, Luiz Carlos de Oliveira (Org.). Inventando a mudança na saúde. São Paulo: Hucitec, 1994. p. 29-88. 
Um método para análise e cogestão de coletivo: a constituição do sujeito, a produção de valor de uso e a democracia em instituições - o método da roda. 1. ed. São Paulo: Hucitec, 2000.

A saúde pública e a defesa da vida. 3. ed. São Paulo: Hucitec, 2006.

CASTANHEIRA, Elen Rose. A gerência na prática programática. In: SCHRAIBER, Lilia Blima (Org.). Programação em saúde hoje. São Paulo: Hucitec, 1990. p. 222-233.

ESCOLA POLITÉCNICA DE SAÚDE JOAQUIM VENÂNCIO (EPSJV). Projeto politico-pedagógico. Rio de Janeiro: Fiocruz, 2005.

GUIZARDI, Francini Lube. Do controle social à gestão participativa: perspectivas pós-soberanas da participação política no SUS, 2008. Tese (Doutorado em Saúde Coletiva) - Universidade do Estado do Rio de Janeiro, Instituto de Medicina Social, Rio de Janeiro, 2008.

GUIZARDI, Francini Lube; CAVALCANTI, Felipe de Oliveira Lopes. A gestão em saúde: nexos entre o cotidiano institucional e a participação política no SUS. InterfaceComunicação, Saúde, Educação, Botucatu, v. 14, n. 34, p. 633-645, jul.-set, 2010.
MERHY, Emerson Elias. Saúde: a cartografia do trabalho vivo. São Paulo: Hucitec, 2005.

MINAYO, Maria Cecília de Souza. O desafio do conhecimento: pesquisa qualitativa em saúde. São Paulo: Hucitec/Abrasco, 1992.

SCHWARTZ, Yves. Trabalho e ergologia. In: SCHWARTZ, Yves; DURRIVE, Louis. (Orgs.). Trabalho e ergologia: conversas sobre a atividade humana. Niterói: Eduff, 2007. p. 25-36.

SALES, Teresa. Raízes da desigualdade social na cultura política brasileira. Revista Brasileira de Ciências Sociais, Rio de Janeiro, v. 9, n. 25, p. 26-37, 1994.

TAVARES, Maria da Conceição. Império, território e dinheiro. In: FIORI, José Luis (Org.). Estados e moedas no desenvolvimento das nações. Petrópolis: Vozes, 1999. p. 449-489.

Recebido em 13/07/2011

Aprovado em 28/07/2012 